\title{
Guiding Students Towards Disciplinary Knowledge With Structured Peer Review Assignments
}

\author{
Vanessa E. Woods \\ University of California, Santa Barbara \\ Margarita Safronova \\ University of California, Santa Barbara \\ Linda Adler-Kassner \\ University of California, Santa Barbara
}

\begin{abstract}
Effective assignments facilitate the connections between course content and disciplinary conventions. We argue that implementation of structured writing and peer review activities can facilitate the connection making process for the students. This paper provides evidence of the positive impact structured writing and peer review activities have on student performance in an Advanced Research Methods Course in Psychology. Results suggest that student participation in structured writing and peer review activities result in higher final paper scores. Further work is needed to explore the mechanism by which structured peer review assignments foster student success in a course and disciplinary community.
\end{abstract}

Keywords: Psychology, research methods, disciplinary membership

\section{INTRODUCTION}

Successful student learning in psychology is contingent on the ability to understand and practice established disciplinary norms and expectations. This ability can be facilitated through implementation of structured writing and peer review assignments that provide students the opportunity to grapple with difficult concepts and writing conventions. This paper shows how low stakes scaffolded writing and peer review assignments facilitated student comprehension of disciplinary practices necessary in a Psychology Research Methods course.

\section{THEORETICAL FRAMEWORK}

Instructors often assume that students intuitively understand the norms and practices of the discipline (e.g. there are norms for how we provide evidence for claims in Psychology). However, if students do not see the explicit connection between course content, how it's presented, and the discipline as a whole, they can feel disconnected. This disconnect discourages students and frustrates professors. An interesting finding that Middendorf and Pace describe from their interviews with faculty, was that when faculty were asked 
about how they would approach problems where students make common mistakes, they found that the faculty were using implicit processes that were not made explicit to students (2004). The dissonance between instructor expectations and student perception is in part due to the varying levels of familiarity with the discipline. In introductory and intermediate college courses, students are disciplinary novices who may not feel or be full members of the disciplinary community (Bransford et al., 2000). In contrast, instructors are experts who have a discipline-specific set of tools that they employ when thinking about the content within a course (Bransford et al., 2000). Instructors intuitively follow norms and conventions of a discipline as a "community of practice" (Lave \& Wenger, 1991; Wenger \& Wenger-Trayner, 2015). In such communities of practice, members share common norms, values, rituals, language, and strategies for learning (Lave \& Wenger, 1991; Wenger \& Wenger-Trayner, 2015). To help students develop expertise so they can become active members of a disciplinary community, they need to gain access to this community of practice, and strategies for how to employ common language and approaches characteristic to a discipline (Lerner, 2015).

Low stakes formative assignments can be effective for helping students develop these strategies. Where high-stakes tests put the responsibility for learning primarily on students without explicit explanation of how they should be treating the course material, low stakes assignments provide students a space to practice their understanding and application of difficult concepts and disciplinary conventions with room for making mistakes that do not have a long-term negative effect on their course performance. Low stakes assignments are designed to guide students to practice a way of thinking that is characteristic of a disciplinary expert, and in general low stakes assignments have been linked to student academic performance, motivation, and confidence (Nicol \& Macfarlane-Dick, 2006).

Courses like the one examined in this study use a combination of low- and high-stakes assessments to enable students to develop and practice the application of concepts and writing conventions that are fundamental to the discipline of psychology. In particular, this course uses structured writing and peer review activities which, research shows, can support learning gains (Halim et al., 2018; Lundstrom \& Baker, 2009; Patchan et al., 2009). In order for students to be successful in the course and have a chance to be active members of the disciplinary community they must be able to understand and apply hard concepts. An obvious and important assertion is that to support learning gains these writing and peer review activities must be highly structured and well designed to help students gain access to disciplinary ways of thinking and practicing (Reynolds \& Moskovitz, 2008). Structured writing and peer review activities can also be seen as facilitating the process of knowledge construction, and instructors need to facilitate opportunities for students to engage in this knowledge construction process as part of their course (Chi \& Wylie, 2014; Meyer, 2012). At its core, this pedagogical practice assumes that learning is an active process requiring knowledge construction and happens within a specific context. In other words, students in this Advanced Research Methods course are constructing knowledge about research in Psychology within the community of Psychologists.

\section{THREE STEPS OF STRUCTURED WRITING AND PEER REVIEW CONSTRUCTION}

Development of structured writing and peer review assignments aimed at disciplinary access consist of three steps. First, the instructor identifies concepts or conventions on which to focus. Second, the instructor creates assignment guidelines with clear links to course and discipline. Third, the instructor develops peer review prompts that are aligned with specific aspects of the concept and/or writing targeted by the assignment

\section{Step 1: Identification of Target Concepts}

In effort to recognize the target concepts, it is important to consider the kinds of questions the students are asking and identify common mistakes in student work related to the concept. These are the clues to what important conceptual jumps the professor needs to fill in for the students. In this Advanced Research Methods course each of the two structured writing and peer review assignments focused on theory and 
rationale in the research paper, and interpretation of statistical analysis results, which had been identified as learning bottlenecks for the students.

For the first assignment the focus was the introduction section of a research paper and how theory should be incorporated into rationale, a critical element of a research paper. The purpose of research in Psychology is to continually test and verify or negate existing theories, and this purpose is reflected in the way that researchers present theories or frameworks to develop testable questions and appropriate hypotheses. This concept is troublesome for students because they often want to focus on their own idea or hypothesis about a phenomenon that they consider to be related to individual or group behaviors rather than consulting the existing theories and frameworks. The idea that the introduction section of a psychology paper includes a rationale that outlines an argument for the hypotheses using theory and previous research as evidence is an accepted way of justifying a research design. Students often misunderstand the goal of an introduction section to simply be a literature review that is devoid of argument, and subsequently struggle writing a strong rationale for their paper

The second disciplinary practice identified was related to the interpretation and presentation of the results in an APA style paper. Students tend to struggle with both the interpretation of and the writing conventions associated with the results section because they have not grasped the concept that there is a pattern in the results related to the type of analyses that are run. Further they do not realize there are disciplinary norms for the interpretation of those findings. Due to their dissociated understanding of the findings, novice students produce results sections that tend to be misinterpreted, disorganized, and not properly formatted. In Psychology, the results allow us to make claims from data about the concept being studied. Students often do not understand that they need to look for patterns in their data analyses, rather than considering the result individually, and that these patterns must always be represented in particular ways of writing (which we tend to refer to in shorthand as "APA style"). The interpretation of main effects and interactions in a factorial design requires the students to make inferences about the two factors being studied and how they are interacting to influence the outcome variable. This is why the interpretation of main effects and interactions in a factorial experimental design requires reporting three sets of findings (in a $2 \times 2$ ) as a package (two main effects and one interaction), and the results are interpreted in the context of those three things together.

\section{Step 2: Design of Writing Assignment}

In this Advanced Research Methods Course, the first writing activity was designed to help the students comprehend the importance of theory in design and to help the students think through the structure and importance of the rationale. The ways of thinking that were made explicit in the structure for the first set of writing and review assignments were: 1) theory is necessary to guide research in Psychology; 2) the rationale is an argument for the hypotheses in the experiment; 3) previous research and statements from theory are evidence to guide a reader towards understanding why the hypothesis predicts what it predicts; and 4) the rationale has to explicitly state the connections between the theory, evidence from other studies, and the hypotheses for the current study. The students were given specific questions to help them understand the purpose of the rationale and a writing sample using an example from the previous laboratory activity.

The second writing assignment enabled students to practice these three ways of thinking about interpreting results: 1) interpretation of results in a $2 \times 2$ design requires discussion of three findings consisting of two main effects and one interaction; 2) the results of the main effects influence how the interaction is interpreted; and 3) APA style has very specific formatting guidelines on how to report the results. The students were given context and a template to use for writing up a 2 x 2 ANOVA and were asked to write up their own results for a single $2 \times 2$ ANOVA using the output file from their data analysis. The previous lab had given the students explicit training on how to read an output file (e.g. where to find the df etc.).

The foundation of each writing task was clear instructions that include the following: 1) stating the purpose of the assignment; 2) providing detailed assignment instructions; and 3) including a sample assignment to serve as a model. The Rationale and Hypotheses and ANOVA writing assignments are both listed in Appendix A. 


\section{Step 3: Design of Structured Review}

The next step was to develop structure review prompts. The goal of the peer review assignment was to give students an opportunity to review the work of others, similar to practice of an expert. This type of activity creates a space where the student can interact with a concept in a different way than simply writing about it. In order for students to be able to provide useful feedback the prompts need to be highly structured. When constructing the peer review it is important to compile a list of items that are important components of a "good" writing assignment. The peer review should also include structured sentence stems to help guide students' commentary on the writing.

The peer review for the Rationale and Hypotheses included a checklist that featured trait identification (trait ID) and a section for open ended feedback. The trait ID included things like: "The author made statements of theory," and "The author made connections between theory and research that justified their hypotheses." For the open ended section of the review students were asked to complete sentence stems that asked them to describe what was in the writing, evaluate the writing, and suggest changes or improvements. The student completed sentence stems related to 1) Describe (The connections that the writer makes are $<$ clear, unclear, logical, hard to follow $>$ because ...) 2) Evaluate (The rationale is <clear, unclear, logical, hard to follow $>$ because.., The hypotheses are <clear, unclear, logical, hard to follow $>$ because..), and 3) Revise (The hypotheses could be revised by..., The connections between theory(ies) and hypotheses could be improved by...) that the students completed. The peer review for the ANOVA write up follows the same structure, and the detailed peer review for both writing assignments is listed in Appendix B.

Our assertion is that structured writing and peer review assignments can be used as a gateway to help students gain disciplinary expertise that will in turn contribute to their ability to construct disciplinary knowledge. Further, when these activities are used more than once in a course they provide the student with multiple opportunities to develop practices to actively navigate and effectively create knowledge within the Psychology course setting. We argue that when students complete low stakes assignments that are intended to provide access to disciplinary practices, such as, correct application of theory to design, and interpretation of results, then they are more likely to receive higher scores on the high-stakes assessment (final paper) because they have had the space to practice with difficult concepts and norms of writing prior to embarking on a larger assignment such as final paper.

\section{METHOD}

\section{Participants}

The participants were students in an upper division research methods course at a R1 four-year institution, and the structured writing and peer review activities were part of the assignments for the course. The writing and peer review activities were based on timely completion and were worth $2.5 \%$ of the overall course grade. We obtained IRB approval to use the students' demographic and course data for analysis (IRB \# 6-20-0296) after the courses had been completed. We aggregated the data from the same course taught by the same professor three times (Winter 2019, Spring 2019, Fall 2019, Total N=249). The same sets of structured writing and review assignments were used in all three quarters. The students were asked to complete two writing assignments and two peer reviews with the same procedures (i.e. same format, instructions, and timeline). The demographics for the students are represented in Table 1. 


\section{TABLE 1 \\ STUDENT DEMOGRAPHICS}

\begin{tabular}{|c|c|c|c|c|}
\hline & Winter 2019 & Spring 2019 & Fall 2019 & Aggregate \\
\hline \multirow{2}{*}{ URM* } & $46 \%$ & $38 \%$ & $32 \%$ & $40 \%$ \\
\cline { 2 - 5 } & 51 & 35 & 14 & 100 \\
\hline \multirow{2}{*}{ Transfer } & $43 \%$ & $37 \%$ & $23 \%$ & $37 \%$ \\
\cline { 2 - 5 } & 48 & 34 & 10 & 92 \\
\hline \multirow{2}{*}{ First generation } & $47 \%$ & $57 \%$ & $43 \%$ & $50 \%$ \\
\hline \multirow{2}{*}{ Pell eligible } & 52 & 53 & 19 & 124 \\
\hline & $42 \%$ & $50 \%$ & $51 \%$ & $47 \%$ \\
\hline
\end{tabular}

\section{Measures and Materials}

We used an online platform called ELI Review to facilitate the writing and review assignments. The director of Professional Development at ELI Review provided feedback on all assignments and review instructions before they were assigned to students. This consultation assured clarity and proper scaffolding of the writing assignment and of the peer review instructions.

The outcome variable in this project was student performance on the final paper in the course. The performance was measured as the total score students received. The paper was a typical APA research report with 4 sections: Introduction, Method, Results, and Discussion and incorporated the elements that students practiced in structured writing and peer review assignments (rationale and results section). The Teaching Assistants assigned to the course graded the papers using the same rubric (see Appendix C). Each quarter there were six Teaching Assistants (TA) and the TAs were randomly assigned a set of papers from a lab to grade that was not their own lab. Over the three courses there were very few repeating Teaching Assistants with each course repetition. The outcome variable (final paper) was worth $30 \%$ of their final course grade.

Student completion of writing and review assignments was operationalized as an additive index. Throughout the quarter the students were asked to complete two writing tasks and two review tasks. Each task was scored as 1 point. If students submitted the writing assignment for the rationale and ANOVA as well as completed reviews of their peer work, they could receive up to 4 points. $85 \%$ of students received all possible points. The data was analyzed using STATA and SPSS.

The regression model reported in the results controls for socioeconomic factors as well as previous academic performance in science courses. The data included admission type (transfer or non-transfer), underrepresented minority status, and Pell grant eligibility. In addition, the models account for science GPA. This GPA is calculated based on the grades the students received in the science courses during their first year. At our campus science GPA has been shown to be the stronger predictor of student performance in course than general university GPA. 


\section{Procedure}

\section{FIGURE 1 \\ TIMELINE OF ASSIGNMENTS AND REVIEWS}

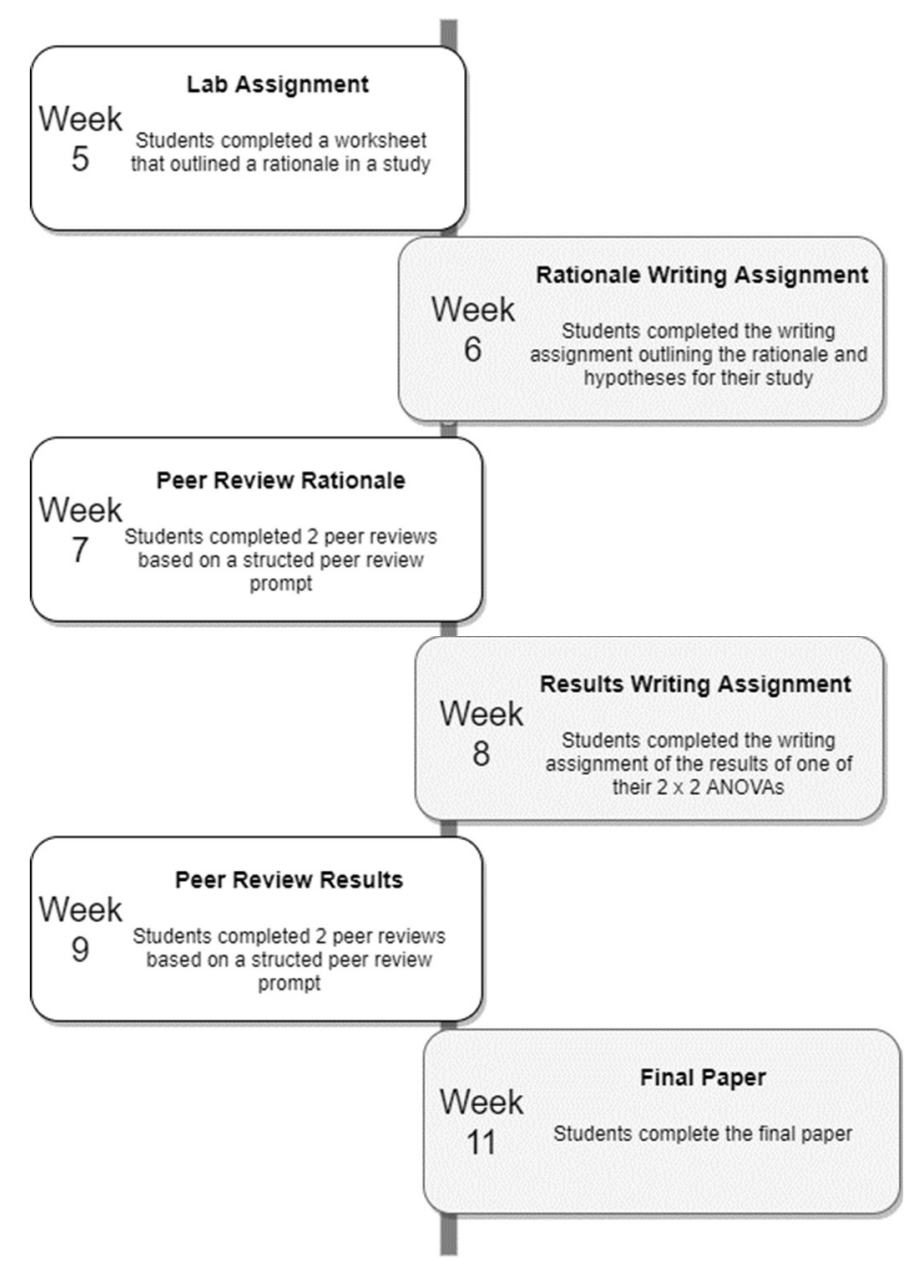

\section{RESULTS}

To analyze the role this assignment played on student academic performance, we conducted a hierarchical regression analysis to look at the effect of completing structured writing and peer review assignments (giving students access to disciplinary practices), while addressing other predictors of students' paper scores in a research methods course. We explored three sets of factors:

1. Factors to control for initial differences in paper scores for the students based on existing scholarship about socio-economic factors and academic performance (Engle \& Tinto, 2008; Graham et al., 2013; Hurtado, 2010; PCAST, 2012; Riegle-Crumb et al., 2019): Pell grant eligibility as an indicator of a low-income background, underrepresented minority (URM) and First-generation status (Gen 1).

2. Cumulative Science GPA as a factor related to students' general academic behaviors (CumSci GPA).

3. The effect of engaging in the structured writing and peer review process (assignment completion) on the student's final paper grade. Factors that we were controlling for were 
entered on Step 1, and Step 2, and the effect of the Writing and Peer Review Activities were entered on Step 3. Results from this analysis are summarized in Table 2.

On Step 1, Pell, URM, and Gen 1 interaction predicted 2\% of the variance in the final paper score of the student $(F(3,242)=2.35, p=0.07)$. However, when considering the regression coefficients, neither variable was a significant predictor of the student's final paper score. On Step 2 we controlled for students' previous academic behaviors by entering CumSci GPA, which explained an additional $4 \%$ of the variance in the student's final paper score, $(F(1,241)=6.12, p=0.01 *)$. The student's cumulative science GPA made a significant unique contribution to the final paper score, with a significant positive beta value. This finding suggests that the variance in students' paper grades are partially explained by their previous academic performance. On Step 3, the effect of the Writing and Peer Review Activities was examined and the number of writing and peer reviewed activities completed explained an additional $29 \%$ of the variance in the student's final paper score, $\left(F(1,240)=81.95, p=0.00^{* *}\right)$. The writing and peer review activities made a significant unique contribution with a significant positive beta value. This effect was much larger than the effect of their previous academic behavior, suggesting that engagement in the structured writing and peer review process is the strongest predictor of the student's paper grade, while controlling for socioeconomic factors and previous academic behavior.

TABLE 2

HIERARCHICAL LINEAR REGRESSION PREDICTING FINAL PAPER GRADE (Z SCORE)

\begin{tabular}{llllll}
\hline \multicolumn{1}{c}{ Effect } & Estimate $(B)$ & $S E$ & \multicolumn{2}{c}{$95 \%$} & \\
\hline & & & $L L$ & $U L$ \\
& & & & & \\
Step 1 & & & & & \\
Adjusted $R^{2}=0.02[F(3,242)=2.35, p=0.07]$ & -0.18 & 0.14 & -0.45 & 0.10 & 0.21 \\
Underrepresented Minority & -0.01 & 0.15 & -0.30 & 0.28 & 0.95 \\
First Generation & -0.25 & 0.14 & -0.52 & 0.30 & 0.08 \\
Pell & & & & & \\
& & & & & \\
Step 2 & & & & & \\
Adjusted $R^{2}=0.04\left[F(1,241)=6.12, p=0.01^{*}\right]$ & -0.12 & 0.15 & -0.40 & 0.16 & 0.40 \\
Underrepresented Minority & -0.01 & 0.15 & -0.30 & .28 & 0.96 \\
First Generation & -0.20 & 0.14 & -0.47 & 0.08 & 0.16 \\
Pell & 0.26 & 0.10 & 0.05 & 0.46 & $0.01^{*}$ \\
Science GPA & & & & & \\
& & & & & \\
Step 3 & & & & & \\
Adjusted $R^{2}=0.29\left[F(1,240)=81.95, p=0.00^{* *}\right]$ & & & & & \\
Underrepresented Minority & -0.21 & 0.12 & -0.46 & 0.30 & 0.08 \\
First Generation & 0.06 & 0.13 & -0.19 & 0.31 & 0.64 \\
Pell & -0.10 & 0.12 & -0.34 & 0.14 & 0.42 \\
Science GPA & 0.19 & 0.09 & 0.02 & 0.37 & $0.03 *$ \\
Peer Review Completion Index & 0.79 & 0.09 & 0.62 & 0.96 & $0.00^{* *}$ \\
& & & & &
\end{tabular}

$* \mathrm{p}<.05 * * p<.001$

\section{DISCUSSION}

We argue that the positive effect of structured peer review assignments is an example of how students can gain disciplinary expertise which influences a student's performance on the final paper. Understanding the disciplinary practices associated with writing research reports is required for producing the "right" kind of writing, as writing must reflect the ability to think through and apply these ideas. In this study, the 
students who have participated in discussing and thinking about the role of theory in Psychology, practiced writing a rationale linked to their hypotheses, and practiced with writing conventions of the discipline have access to disciplinary knowledge and ways of writing; hence, they should write the introduction of their papers in fundamentally different ways. The findings show that students are more likely to exhibit practices characteristic of the disciplinary community when they have had the opportunity to hone their skills in the context of low-stakes assignments. While this study does not provide direct evidence that the students feel like they are members of the disciplinary community, their academic performance can serve as a proxy for their ability to successfully participate and complete a course that is associated with the foundation of the discipline.

The findings align with research on learning and writing (e.g., National Research Council 1999; National Academies 2018) showing that low stakes assignments in which students use writing to think through challenging ideas produce learning gains (Halim et al., 2018; Lundstrom \& Baker, 2009; Patchan et al., 2009). Studies also suggest that writing and providing feedback develops critical thinking skills (Prichard, 2005; Reynolds \& Moskovitz, 2008; Shultz \& Gere, 2015), but the mechanisms for these learning gains remain largely unexplored. The writing and peer review assignments were designed 1) with access to disciplinary writing practices in mind and 2) to provide students with scaffolded opportunities to construct knowledge. However, this was not tested with a true experimental design (i.e. there was not a group of students who did writing and peer review assignments that were not aimed at disciplinary writing practices). It is not pedagogically ethical to set up a control group to do an assignment that is predicted not to help the student. This is anathema to excellent teaching practices, and as such is a limitation to the current study we willingly acknowledge.

While we believe the current results provide evidence that access to disciplinary knowledge can impact student success, these results are preliminary in nature and could have relatively limited generalizability. The data from this sample is from the same course with the same instructor over time. While there were no significant changes in the structured writing and peer review assignments, and a relatively random grading scheme with the same paper rubric, this study does not control for changes in the class or student population over time. We did try to account for any idiosyncratic effects of each specific class and ran the data analyses by course (data not shown); and got the same pattern of results, so chose to present the aggregate data analysis only. However, given these points the generalizability of this data set is limited. Our goal is to gather data from a diverse set of courses using structured writing and peer review assignments and to develop a measure of disciplinary membership in order to test the assertion that structured writing and peer review activities do in fact grant access to disciplinary practices that have effects on student learning and performance.

The positive effects of the structured writing and peer review activities are clear in this particular study; however, we do not have data related to the specific mechanisms of this effect. It is possible that the reflective process leads to increases in metacognitive strategies related to what works in that particular learning framework (Schraw \& Dennison, 1994; Young \& Fry, 2008). There is evidence that reflective processes (i.e. peer review) increase students' metacognitive abilities, with respect to their own learning (McAlpine et al., 1999). However, there is no research that lays out a clear path from peer review to increase in metacognitive strategies to student success in this course.

In addition to development of metacognitive strategies, we propose that these structured writing and peer review activities can help students feel like psychologists. This proposal employs the concept of disciplinary membership (I feel like a psychologist) as an intersection of sense of academic belonging and science identity (c.f. Trujillo \& Tanner, 2017). Science identity has been conceptualized as an intersection of performance, recognition, and competence in scientific practices (Carlone \& Johnson, 2007). Scholarship on sense of belonging has shown that there is a positive relationship between sense of belonging and college persistence (Freeman et al., 2007; Hurtado \& Carter, 1997). Scholars have argued that, like a sense of belonging, science identity is integral to student persistence (Brickhouse et al., 2000; Seymour \& Hunter, 2019; Tobias, 1994). However, there is an identified gap in the scholarship on the role of academic sense of belonging and science identity within the context of psychology. The next set of studies in our laboratory are set up to test if increases in metacognition and sense of disciplinary membership, as suggested 
mechanisms, are in fact explaining how the structured writing and peer review process is increasing student success.

In conclusion, the data suggests that structured writing and peer review assignments aimed at developing students' access to the discipline and fosters opportunities for knowledge construction manifests in increases in students' understanding and performance on assessments. These data should be interpreted with the acknowledgement of the limitations of the methodology, and the generalizability of the study.

\section{REFERENCES}

Bransford, J., National Research Council (U.S.), Committee on Developments in the Science of Learning, National Research Council (U.S.), \& Committee on Learning Research and Educational Practice. (2000). How people learn: Brain, mind, experience, and school. National Academy Press. Retrieved from http://site.ebrary.com/id/10038789

Brickhouse, N.W., Lowery, P., \& Schultz, K. (2000). What Kind of a Girl Does Science? The Construction of School Science Identities. Journal of Research in Science Teaching, 37(5), 441458. https://doi.org/10.1002/(SICI)1098-2736(200005)37:5<441::AID-TEA4>3.0.CO;2-3

Carlone, H.B., \& Johnson, A. (2007). Understanding the science experiences of successful women of color: Science identity as an analytic lens. Journal of Research in Science Teaching, 44(8), $1187-$ 1218. https://doi.org/10.1002/tea.20237

Chi, M.T.H., \& Wylie, R. (2014). The ICAP Framework: Linking Cognitive Engagement to Active Learning Outcomes. Educational Psychologist, 49(4), 219-243. https://doi.org/10.1080/00461520.2014.965823

Engle, J., \& Tinto, V. (2008). Moving beyond access: College success for low-income first-generation students. The Pell Institute for the Study of Opportunity in Higher Education.

Freeman, T.M., Anderman, L.H., \& Jensen, J.M. (2007). Sense of Belonging in College Freshmen at the Classroom and Campus Levels. The Journal of Experimental Education, 75(3), 203-220. https://doi.org/10.3200/JEXE.75.3.203-220

Graham, M.J., Frederick, J., Byars-Winston, A., Hunter, A-B., \& Handelsman, J. (2013). Increasing Persistence of College Students in STEM. Science, 341(6153), 1455-1456. https://doi.org/10.1126/science. 1240487

Halim, A.S., Finkenstaedt-Quinn, S.A., Olsen, L.J., Gere, A.R., \& Shultz, G.V. (2018). Identifying and Remediating Student Misconceptions in Introductory Biology via Writing-to-Learn Assignments and Peer Review. CBE_Life Sciences Education, 17(2), ar28. https://doi.org/10.1187/cbe.17-100212

Hurtado, S. (2010). Degrees of Success: Bachelor's Degree Completion Rates among Initial STEM Majors. Higher Education Research Institute at UCLA. Retrieved from www.heri.ucla.edu/nih

Hurtado, S., \& Carter, D.F. (1997). Effects of College Transition and Perceptions of the Campus Racial Climate on Latino College Students' Sense of Belonging. Sociology of Education, 70(4), 324. https://doi.org/10.2307/2673270

Lave, J., \& Wenger, E. (1991). Situated Learning: Legitimate Peripheral Participation (1st ed.). Cambridge University Press. https://doi.org/10.1017/CBO9780511815355

Lerner, N. (2015). Writing is a Way of Enacting Disciplinarity. In L. Adler-Kassner \& E. Wardle (Eds.), Naming What We Know: Threshold Concepts of Writing Studies (pp. 40-42). Utah State University Press.

Lundstrom, K., \& Baker, W. (2009). To give is better than to receive: The benefits of peer review to the reviewer's own writing. Journal of Second Language Writing, 18(1), 30-43. https://doi.org/10.1016/j.jslw.2008.06.002

Mayer, R.E. (2008). Applying the science of learning: Evidence-based principles for the design of multimedia instruction. American Psychologist, 63(8), 760-769. https://doi.org/10.1037/0003066X.63.8.760 
McAlpine, L., Weston, C., Beauchamp, C., Wiseman, C., \& Beauchamp, J. (1999). Building a Metacognitive Model of Reflection. Higher Education, 37(2), 105-131. https://doi.org/10.1023/A:1003548425626

Middendorf, J., \& David Pace. (2004). Decoding the disciplines: A model for helping students learn disciplinary ways of thinking. New Directions for Teaching, 98, 1-12.

Nicol, D.J., \& Macfarlane-Dick, D. (2006). Formative assessment and self-regulated learning: A model and seven principles of good feedback practice. Studies in Higher Education, 31(2), 199-218. https://doi.org/10.1080/03075070600572090

Patchan, M.M., Charney, D., \& Schunn, C.D. (2009). A validation study of students' end comments: Comparing comments by students, a writing instructor, and a content instructor. Journal of Writing Research, 1(2), 124-152.

PCAST. (2012). Engage to Excel: Producing One Million Additional College Graduates with Degrees in Science, Technology, Engineering and Mathematics. President's Council of Advisors on Science and Technology, U.S. Government Office of Science and Technology.

Prichard, J.R. (2005). Writing to Learn: An Evaluation of the Calibrated Peer Review ${ }^{\mathrm{TM}}$ Program in Two Neuroscience Courses. Journal of Undergraduate Neuroscience Education, 4(1), A34-A39.

Reynolds, J., \& Moskovitz, C. (2008). Calibrated Peer Review Assignments in Science Courses: Are They Designed to Promote Critical Thinking and Writing Skills? Journal of College Science Teaching, 38(2), 60-66.

Riegle-Crumb, C., King, B., \& Irizarry, Y. (2019). Does STEM Stand Out? Examining Racial/Ethnic Gaps in Persistence Across Postsecondary Fields. Educational Researcher, 48(3), 133-144. https://doi.org/10.3102/0013189X19831006

Schraw, G., \& Dennison, R. S. (1994). Assessing Metacognitive Awareness. Contemporary Educational Psychology, 19(4), 460-475. https://doi.org/10.1006/ceps.1994.1033

Seymour, E., \& Hunter, A-B. (Eds.). (2019). Talking about Leaving Revisited: Persistence, Relocation, and Loss in Undergraduate STEM Education. Springer International Publishing. https://doi.org/10.1007/978-3-030-25304-2

Shultz, G.V., \& Gere, A.R. (2015). Writing-to-Learn the Nature of Science in the Context of the Lewis Dot Structure Model. Journal of Chemical Education, 92(8), 1325-1329. https://doi.org/10.1021/acs.jchemed.5b00064

Tobias, S. (1994). They're not dumb, they're different: Stalking the second tier: an occasional paper on neglected problems in science education. Research Corporation.

Trujillo, G., \& Tanner, K.D. (2017). Considering the Role of Affect in Learning: Monitoring Students' Self-Efficacy, Sense of Belonging, and Science Identity. CBE-Life Sciences Education. https://doi.org/10.1187/cbe.13-12-0241

Wenger, E., \& Wenger-Trayner, B. (2015). Introduction to communities of practice |Wenger-Trayner. Retrieved from https://wenger-trayner.com/introduction-to-communities-of-practice/

Young, A., \& Fry, J.D. (2008). Metacognitive Awareness and Academic Achievement in College Students. Journal of the Scholarship of Teaching and Learning, 8(2), 1-10. 


\section{APPENDIX A}

The two writing assignments instructions and samples provided for the students 1) Rationale and Hypotheses and 2) ANOVA Write Up

\section{PSY120L Rationale \& Hypotheses Assignment}

\section{Instructions}

\section{$\underline{\text { Purpose and Overview }}$}

Your research manuscript includes four sections: introduction, methods, results, and discussion.

This assignment is to help you write the rationale (including your hypotheses) for your research manuscript. The rationale and hypothesis will serve as the outline for your Introduction. Writing a clear rationale that enables readers to connect theory and observations to your hypotheses is critical for writing a successful manuscript.

You will work on this crucial piece of your manuscript by:

1) completing this brief writing prompt

2) providing peer review on others' writing and receiving feedback on your own writing

3) revising based on feedback.

The process of writing, receiving feedback, and revising is central to scientific practice. Research also demonstrates that this process supports more effective learning and application of ideas.

\section{Assignment}

Write an outline of the rationale for your research manuscript that is based on your group's experiment. Your outline of your rationale must include statements of theory and observations from research. These should be linked such that readers understand HOW they serve as justification for your hypotheses. Your rationale also must therefore end with a statement of your hypotheses. These hypotheses should be stated using the form and language that Dr. Woods has outlined.

When you write your rationale, BEGIN with language that focuses on what "researchers show..."

END with "Our study will..." (and state your hypotheses).

Sample Rationale and Hypotheses provides an illustration of an outline of a rationale and associated hypotheses.

After you write your outline of the rationale and hypotheses, you will provide feedback to writers from other research groups on their rationale. You will then revise your rationale based on their comments before you submit it to your TA for additional feedback.

\section{Sample Assignment Provided to the Students}

\section{Design}

IV = Learned Helplessness (try to solve unsolvable anagrams) vs no Learned Helplessness (solve solvable anagrams)

Moderator $=$ Fixed vs. Growth Mindset

$\mathrm{DV}=$ Persistence in a maze task 


\section{Sample Rationale}

- Self Determination Theory argues that if you feel you have agency (feel you have control or ability to change your environment) you will be motivated to gain mastery over a task or problem (figure out how to do something well)

- Learned helplessness is associated with depression and a lack of behavior because people feel they do not have control over their environment

- Learned helplessness is a phenomenon that affects people's motivation and willingness to persist

- Student success is affected by many factors, one of which is motivation and persistence in the face of challenges

- Motivation to persist is important in student success

- Motivation to continue in the face of challenges and hardship is something that varies by people and by situation

- Fixed mindset is associated with a greater propensity for learned helplessness attributions and behavior and less persistence

- Learned helplessness can be seen in students when they decide that they are not good at a particular domain and their performance in that domain suffers

\section{Links/Connections}

Learned helplessness reduces motivation and leads to less persistence in challenging tasks. People with a fixed mindset will be more sensitive to this effect as they are more likely to make learned helpless attributions for a situation. Less persistence and giving up in the face of challenges will negatively impact student success.

\section{Sample Hypotheses}

Main Effect: Those participants who are in the induced learned helplessness condition will show less persistence in solving mazes compared to those participants that did not experience learned helplessness.

Moderator Effect: Those participants with a fixed mindset will show less persistence in solving mazes compared to those participants that did not experience learned helplessness.

Interaction: Those participants who are in the induced learned helplessness condition will show less persistence in solving mazes compared to those participants that did not experience learned helplessness, and this effect will be more pronounced in those who have a fixed mindset compared to a growth mindset.

\section{PSY120L ANOVA Write Up Assignment}

\section{Instructions}

\section{$\underline{\text { Purpose }}$}

You will practice writing up an ANOVA to improve the quality of the results section of your research manuscript.

\section{Assignment}

You will write up the results for one $2 \times 2$ ANOVA from your experiment, using correct APA format. Your write up should be no more than one page, and should be directly and clearly explained using appropriate notation. You should use the template provided by Dr. Woods below. 


\section{Templates}

Click here to view the template you should use to write up your 2x2 ANOVA ANOVA template

Can't remember where to get the numbers you are reporting? Click here for an example of where to find the information you need for your ANOVA write up from your SPSS output ANOVA SPSS Output Sample

\section{Background Information Using an Example}

Imagine a study where researchers manipulate two variables at the same time. For example: they manipulate the sunlight (low vs. high) and water (low vs. high) a plant receives, and then measure the height of the plant.

The researchers use specific language to refer to the notation of factors included in this study (that we have gone over in class):

Experimental Factor Notation = number of levels/conditions of the variable When researchers write this, they use the following notation: number (name of variable with conditions). The study with the plants, then, would look like this:

2 (Sunlight: Low vs. High) x 2 (Water: Low vs. High) between subjects design on the DV of plant height. This would be referred to as a $2 \times 2$ study (because there are two variables being manipulated with two conditions each).

For this assignment, you will write the main effects and interaction of one of the $2 \times 2$ s from your experiment. Your write-up should consider the effects of one factor at a time on the dependent variable (DV).

Ultimately, your write up should include:

- Experimental notation ("We ran a $2 \times 2$ on...")

- Main effect 1

- Main effect 2

- Interaction

When you write your main effects and interactions, it's important to remember that factors can be independent variables or moderators.

In the example above, the first the main effect of factor 1 (independent variable IV1) and the second main effect of factor 2 (independent variable IV2) would be considered separately. In the example the first main effect would be to look at the effect of high and low sunlight on the height of the plant (while "ignoring" or averaging across the effect of water). The second main effect would be to look at the effect of high and low water on the height of the plant (while "ignoring" or averaging across the effect of sunlight).

Interaction is considering the effects of both factors on the DV at the same time. In the plant example we would look at the joint effect of sunlight (IV1) and water (IV2) on plant height.

\section{ANOVA Template Provided to the Students}

The data was analyzed using a 2 (IV level 1 vs. IV level 2) x 2 (Moderator level 1 x Moderator level 2) ANOVA on [DV].

The main effect of IV1 on the DV was [significant/non-significant] $(F$ [df, df] $=$ $p=$ , Ms $=$ and ___ [make sure to indicate what each mean is referring to). This indicates that the main effect of [IV1] on [DV] was [explain in words].

The main effect of Moderator on the DV was [significant/non-significant] $(F[\mathrm{df}, \mathrm{df}]=\ldots p=\ldots, M s$ $=$ _ and ___ [make sure to indicate what each mean is referring to). This indicates that the main effect of [Moderator] on [DV] was [significant/not significant]. This indicates the main effect of [Moderator] on [DV] was [explain in words]. 
The interaction effect of [IV1] and [Moderator] on [DV] was [significant/not significant] $(F[\mathrm{df}, \mathrm{df}]=$ $p=\_$). [compare cell means here] This indicates that the interaction between [IV1] and [Moderator] on [DV] was [explain in words].

Note: you follow this template for this assignment, and use it as a guideline for your paper. If you write it out exactly as it's written above for your paper, that is considered the bare minimum, and you will receive points for providing all of the necessary information (make sure to follow along with the rubric). However, you will also be graded on writing quality - if you can use this format but make it flow/transition more smoothly, this will increase the quality of this section (and make it seem less repetitive).

\section{ANOVA SPSS Output Example Provided to the Students}

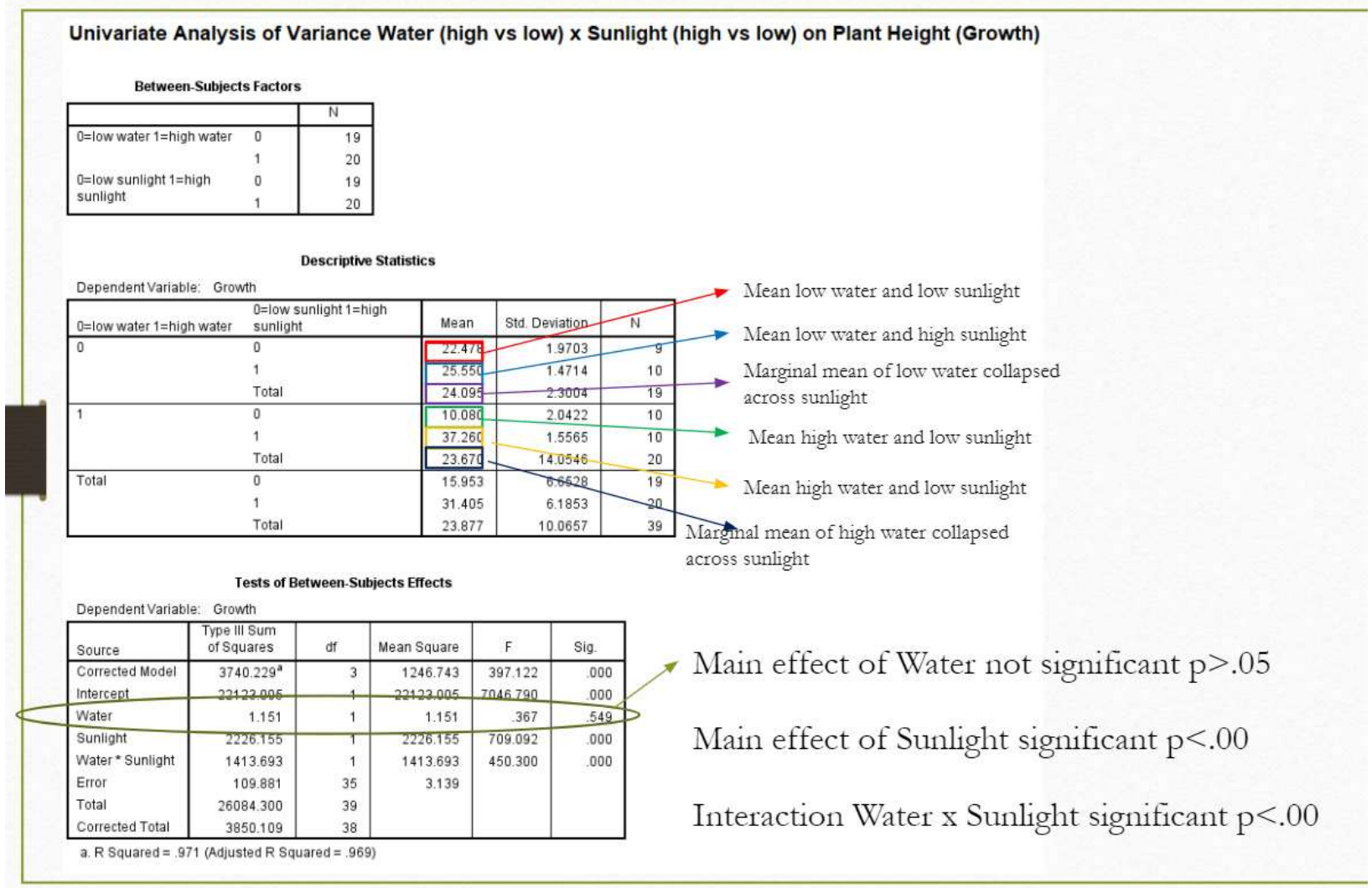




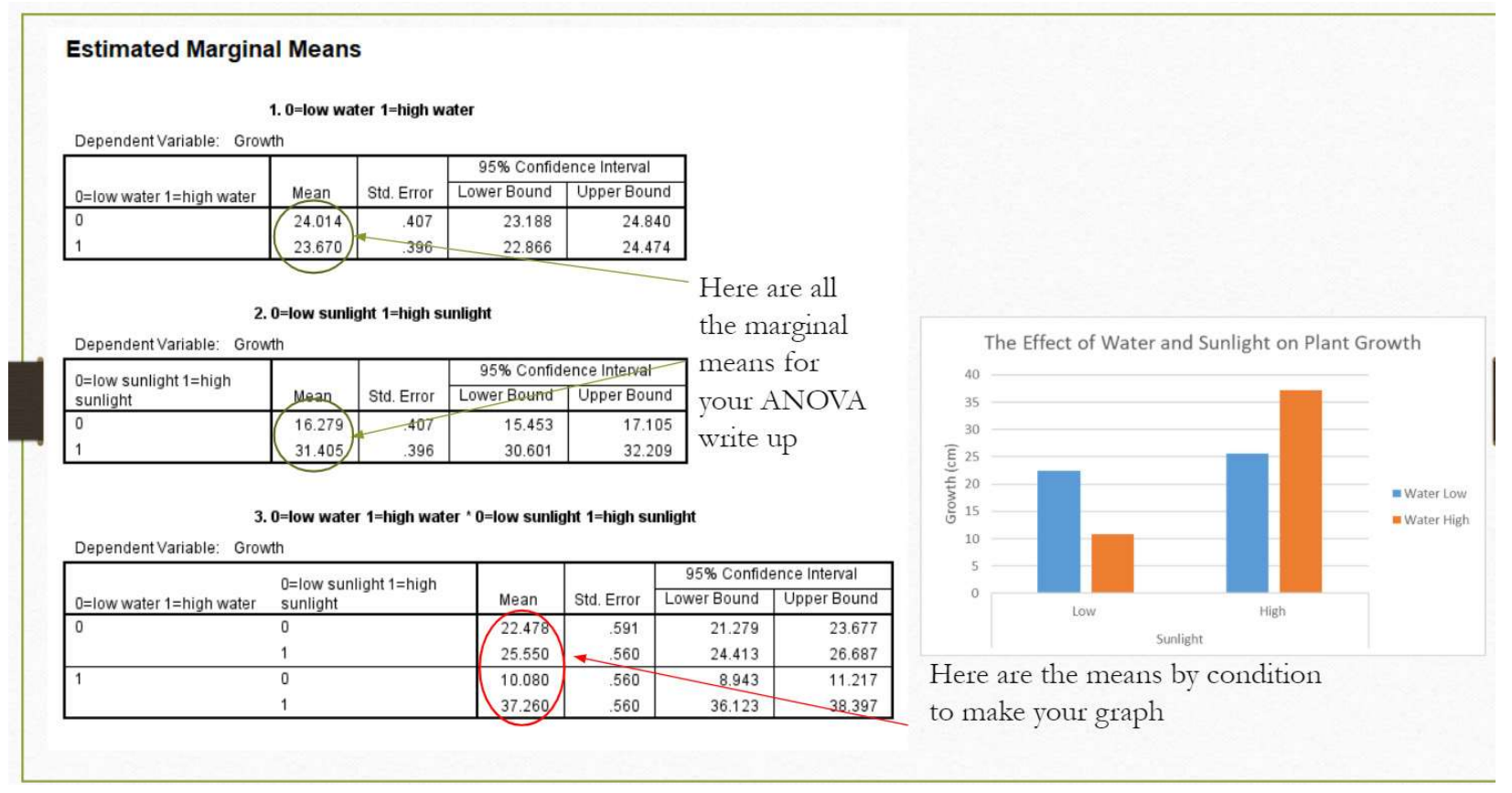

\section{APPENDIX B}

The two peer review instructions and samples provided for the students 1) Rationale and Hypotheses and 2) ANOVA Write Up

\section{PSY 120L Rationale \& Hypotheses Review Instructions}

\section{Instructions}

To review your colleagues' work:

Skim the peer review criteria and questions below, so that you have them in mind as you read.

Read through each colleague's draft twice. The first time, don't provide feedback. After you have read the entire draft, go back through and re-read, using the criteria for peer review.

When giving written feedback, write the kind of comment that you would like to receive.

Note: A comment that provides big-picture advice on content, organization, or terminology is helpful; a comment focusing on syntax and mechanics (aka "grammar") or one that says the writing is "great" is less helpful.

\section{Trait Identification}

Check the boxes next to each of the components of the rationale that you see in this draft.

- Statements of theory

- Observations from research

- Connections between theory and research that justify hypotheses

- Correctly stated hypotheses

\section{Contextual Comments}

Please finish the prompts below with one to two sentences for each number to provide feedback to the author

Describe:

1) The connections that the writer makes are (clear, unclear, logical, hard to follow) because 


\section{Evaluate:}

1) The rationale is (clear, unclear, logical, hard to follow) because

2) The hypotheses are (clear, unclear, logical, hard to follow) because

\section{Suggested Revisions:}

1) The hypotheses could be revised by

3) The connections between theory(ies) and hypotheses could be improved by

\section{PSY 120L Results ANOVA Review Instructions}

\section{Trait Identification}

Please check the following boxes if the submission meets all of the requirements

- Factor notation is correctly written - \#(factor: levels/conditions) x \#(factor: levels/conditions) on DV

- The draft uses correct language to describe main effect 1 e.g. There was or was not a significant main effect of factor on DV $F(\mathrm{df}, \mathrm{df})=f$ value, $\mathrm{p}$ value.

- The draft explains the meaning of main effect 1 using language that is clear and accessible to an audience unfamiliar with statistical operation

- The draft uses correct language to describe main effect 2 - There was or was not a significant main effect of factor on DV F (df, df $)=f$ value, $p$ value.

- The draft explains the meaning of main effect 2 using language that is clear and accessible to an audience unfamiliar with statistical operation.

- The draft uses correct language to describe interaction - There was or was not a significant interaction of both factors on the DV F (df, $d f)=f$ value, $p$ value.

- The draft explains the meaning of the interaction using language that is clear and accessible to an audience unfamiliar with statistical operation.

\section{Rating Scales}

Was this ANOVA clearly written? Rate it out of 5 stars.

- 1 star=Unclear or wrong information/order or missing both main effects or interaction

- 2 stars=Missing or incorrectly stated main effect or interaction

- 3 stars=adequate (has main effects and interaction) missing explanation

- 4 stars $=$ Correctly states main effects and interaction and has explanation that is clear

- 5 stars=Exemplary explanation of the main effects and interaction

Final Comment

Please write 2-4 sentences that explain why you gave the "star" rating that you did. 